\title{
Biology and Feeding Preferences of Spodoptera Frugiperda (Lepidoptera: Noctuidae) On Maize And Selected Vegetable Crops
}

\author{
D.M.I.J.Wijerathna $^{1 *}$, P.H.Ranaweera ${ }^{2}$, R.N.N.Perera ${ }^{1}$, M.L.M.C.Dissanayake ${ }^{1}$ and J.B.D.A.P. \\ Kumara $^{1}$
}

Date Received: $29^{\text {th }}$ March 2020 / Date Accepted: $10^{\text {th }}$ July 2020

\begin{abstract}
Purpose: Fall Armyworm, Spodoptera frugiperda (J. E. Smith) (Lepidoptera, Noctuidae) was recently reported for the first time in Sri Lanka in Oct 2018 as a new invasive pest of maize. Therefore, the objectives of present study were to study biology and to evaluate feeding preferences of S. frugiperda on maize and selected vegetable crops.

Research Method: During the experiment, newly hatched larvae were fed with maize, cabbage, okra, beans, radish and brinjal leaves under laboratory conditions. Maize was used as the positive control. Duration of development from larva to adult, pupal weight, pupal length, sex ratio, survival percentage, and oviposition (Choice and No-Choice test) on different vegetable crops were evaluated.
\end{abstract}

Findings : Results of the feeding preference test envisaged that there was no host dependent variability among neonate larvae for maize, cabbage, raddish and brinjal. The highest damage (50-75\%) was reported in larvae fed on okra, and (25-50\%) damage was showed in beans after 24 hours of inoculation. The highest survival percentage of larvae (80\%) and shortest larval development period (23.8 0.3 days) were reported in larvae fed with maize where as it was the longest in brinjal. The highest oviposition (4.1 \pm 1.2 in Choice

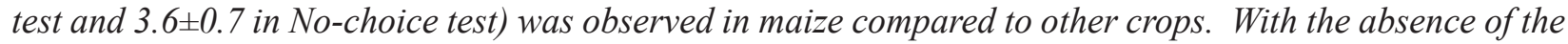
most preferred host (maize) for oviposition, other hosts were used by the pest. During the off season Fall armyworm could survive in alternate crops.

Research Limitations : Field observations were not carried out to confirm (validate) the laboratory observations with the time limitation.

Originality/Value : The research provides interest and idea about the survival mechanism of S. frugiperda during off season of maize and potential alternative host plants of the pest. It identifies the possibility of moving of S. frugiperda into five vegetable crops and thereby make awareness of the farmers about the pest to follow the suitable management practice of the S. frugiperda.

Keywords: Alternative host plant, Emergence, Oviposition, Sex ratio, Survival

\section{INTRODUCTION}

The Fall Armyworm (FAW) Spodoptera frugiperda (J.E. Smith) (Lepidoptera: Noctuidae), has been (recorded as a) identified as a sporadic, polyphagous and migratory pest species in the world (Hardke et al., 2015). Food and Agriculture Organization of the United Nations reported that $S$. frugiperda is native to tropical and sub-tropical regions of America and was first reported in Africa in 2016. All around the world, maize crop was damaged by $S$. frugiperda larvae. Moreover, high reproductive rate of the pest and occurrence of several generations per single year lead to high crop damage.

\footnotetext{
Department of Export Agriculture, Faculty of Agricultural Sciences, Sabaragamuwa University of Sri Lanka

Imalkawijerathna773@gmail.com

2 Horticultural Crop Research and Development Institute, Gannoruwa, Peradeniya, Sri Lanka

D http://orcid.org/0000-0003-3079-4668
} 
In Sri Lanka, the pest infestation was first reported at Damana region in Ampara district (Perera et al., 2019). Later, it was reported in Anuradhapura, Monaragala, Kurunegala, Kandy, Badulla and Ratnapura districts and almost 50\% of Sri Lankas' maize cultivations were infested by S. frugiperda during 2018/19 Maha season. Almost all growth stages of the Maize crop can be seriously infested by the pest and the latter stage larva consumes high compared to initial stages (Perera et al., 2019).

The pest undergoes a complete metarmorphosis and the pest biology is greatly influenced by the tropical climatic conditions and available host plants. Accurate identification of pest life cycle, growth characteristics, feeding preferences and host preferences for oviposition are important to understand the biology of the pest and pest biology is very important in planning effective pest control. Host preference of the pest could be varied with larval instar (age) and their survival might be different with the type of host plants (Perera et al., 2019, Rojas et al., 2018). Moreover, biological variables such as duration of larval period, pre-pupae (non-feeding stage between the active larva and pupa), pupae and total period from larva hatching to adult emergence (days), pupae weight and length, sex ratio, and survival percentage can be varied with the different host plants (Silva et al., 2017). Even though, biology and feeding preferences of $S$. frugiperda were reported from African, American and other regions of the world, limited information were reported under local conditions where behaviors could be completely different. Addition to damage on maize, the pest could be infested to other field crops (cereals, fruit and vegetable crops) under local environment conditions. Studies showed that performances of FAW in different host plants vary including their longevity, survival and ovipossition (Fei. Guo et al., 2020). Detailed investigation of FAW's performances on different alternative host plants serves the best to predict types of other host plants in a threat with the absence of preferred host. Therefore, the main objective of present study was to identify the biology and feeding preferences of $S$. frugiperda on selected vegetable crops under laboratory conditions.

\section{MATERIALS AND METHODS}

\section{Host Plants and Crop Establishment}

The experiment was conducted as a pot-trial at Horticultural Crop Research and Development Institute, Sri Lanka (HORDI). Accordingly, five vegetable crops namely, cabbage (Brassica oleracea) Exotic f1 variety, okra (Hibiscus esculentus) variety MI5, beans (Phaseolus vulgaris) variety Gannoruwa green, radish (Raphanus sativus) variety Beeralu, brinjal (Solanum melongina) variety Lenairi and one cereal maize (Zea maize) variety Pacific were used as host plants and maize was considered as reference host. Potting media was prepared, using sand: top soil: compost at 1:1:1: ratio. Seeds of selected crop were sawn in nurseries and two weeks old seedlings were transplanted to pots. Plant nutrition management was done as per the Department of Agriculture (Sri Lanka) recommendations (Anonymous, 1992). Crops were managed without applying any pesticides and allowed growing until 8-10 leaf stage before introducing $S$. frugiperda neonate larvae.

\section{S. frugiperda Culture Preparation}

Egg masses were collected from S. frugiperda rearing unit at Horticultural crop Research and Development Institute and kept inside plastic cups with proper ventilation. To keep the freshness, a wet tissue paper was kept inside the plastic cup before introduction of leaf with egg masses. On an average 2-3 days were taken to hatch above egg mass. Larvae that just after hatched were separated and were used to inoculate host plants. Larvae were fed daily with fresh maize leaves and clean culture environment was maintained inside to avoid contaminations. Pupae were separated into separate cup and kept inside cages until the emergence of moths. Cotton soaked sugar solution and water were supplied for moths.

\section{Lifecycle of S. frugiperda on different host plants}

Leaf samples from six selected crops were placed in six different plastic containers and ten 
neonate larvae were introduced to each. The experiment was replicated three times. Larvae were kept inside the plastic cups $(10 \mathrm{~cm}$ diameter and $7 \mathrm{~cm}$ height) until they complete the lifecycle (i.e. emergence of the moths) and number of days taken to complete each stage of life cycle was recorded. By assuring adequate food supply, all larvae were fed daily with specific fresh leaf samples. Larvae were fed using same leaf areas of each selected crops. These larvae were observed daily to assess their life cycle variables such as duration of larvae to pupation, pupae to emergence of adult, total days to complete the life cycle, male and female pupae weight (g) (measured at 24 hours after pupation), number of females to male sex ratio, and survival percentage (number of larvae complete the lifecycle).

\section{Host-plant preference for oviposition}

Host preference of females for oviposition was studied under laboratory conditions. This experiment was done by two methods as Choice test and No-Choice test. Selected plants (cabbage, okra, beans, radish, brinjal and maize) at similar growth stages (plants having 8 to 10 fully expanded leaves) were placed inside screen cages and female and male moths (4-5 days old) were introduced to each cage at 1:1 ratio ( 6 female and 6 male moths per cage). The experiment was replicated six times and sugar solution and water were supplied to feed the moths.

In Choice test all tested vegetable crops were randomly placed inside the cages $(4 \mathrm{ft} \times 1.5 \mathrm{ft} \times 2.5 \mathrm{ft})$ and moths ( 6 female and 6 male moths per cage) were released allowing them to select most preferable host plant for oviposition. This was replicated six times. In No-Choice test out of six plants one host was kept inside the cage at a time $(46 \mathrm{~cm} \times 41 \mathrm{~cm} \times 43 \mathrm{~cm})$ and moths ( 1 female and 1 male per cage) were introduced. This was replicated six times. After five days, egg masses were collected from both Choice and No-Choice tests and were used to estimate number of egg masses in each treatment, number of eggs per egg mass and length of the egg mass $(\mathrm{cm})$.

\section{Feeding preference of neonate larvae to selected crops}

This was designed to evaluate the feeding preference of the pest under laboratory condition. Similar size $(2 \mathrm{~cm} \times 4 \mathrm{~cm})$ leaf samples (same maturity) from each host were kept randomly inside the plastic container $(24 \mathrm{~cm} \times 12 \mathrm{~cm} \times 7 \mathrm{~cm})$. To keep the freshness, wetted tissue papers were laid on the bottom of plastic container and 20 neonate larvae were introduced into middle of the container. This experiment was replicated for ten times and damage was recorded as described in Ayala et al. (2013).

Damage scale

1- No damage

2- $<25 \%$

3- $25 \%-50 \%$

4- $50 \%-75 \%$

5- $75 \%-100 \%$

Moreover, feeding preference of each host was recorded at $1 \mathrm{~h}, 3 \mathrm{~h}$, and $24 \mathrm{~h}$ and $48 \mathrm{~h}$ time intervals, by visual observation according to the above scale.

\section{Statistical Analysis}

Data was statistically analyzed using Statistical Analysis Software (SAS) packages. Parametric Data were analyzed using Analysis of Variance (ANOVA) and mean separation was done by using Duncan Multiple Range Test (DMRT) at $5 \%$ interval. Categorical data analysis procedures were used to analyze non parametric data and significance of the treatment effects was obtained at $\mathrm{p}<0.05$ level. The Microsoft Excel (2010) computer software Package was used to prepare graphs. 


\section{RESULTS AND DISCUSSION}

\section{Lifecycle of $S$. frugiperda on different host plants}

Tested crops had a significant effect $(\mathrm{p}<0.0001)$ on life cycle length of $S$. frugiperda . The Larvae that fed on maize complete their larvae period in $16.0 \pm 0.2$ days and that was the shortest among the tested crops. Larval period on cabbage (21.4 \pm 0.3 days) was shorter than that of okra (23.5 \pm 1.0 days), beans (23.5 \pm 0.0 days) and brinjal (23.6 0.8 days). However, larval period of cabbage was not significantly different from the radish ( $23.0 \pm 0.5$ days).

Pupae period was significantly shorter in beans ( $7.2 \pm 0.5$ days), brinjal ( $7.3 \pm 0.5$ days) and okra (7.2 \pm 0.5 days) compared to cabbage $(9.1 \pm 0.3$ days) and radish ( $9.4 \pm 0.3$ days). However, none of the above were different from maize $(7.9 \pm 0.2$ days) pupae period. Considering both larvae and pupae period together (larvae to adult period) larvae feed on maize ( $23.8 \pm 0.3$ days) took the shortest time to emerge adult and that was significantly different from all other host plants.

Type of host plants is significantly affected $(p<0.0004)$ on pupae growth in term of their length and weight (Table 01). Accordingly, the highest pupae length $(1.7 \pm 0.02)$ was observed in maize and that was the lowest in okra and beans (1.4 \pm 0.05 and $1.3 \pm 0.04)$. Significantly greater male and female pupae weights were observed in maize in comparison to all other crops (Table 01). Weight of male pupae was not significantly different between cabbage, okra, beans, radish and brinjal. However, that for female was the lowest in vegetables than maize.

Male larvae survival percentage (number of larvae complete their lifecycle of $S$. frugiperda) was the highest in radish $(36 \%)$ and in maize it was $33 \%$. That was the lowest in Okra $(0 \%)$, Beans $(6 \%)$ brinjal (3\%).Significantly greater female larvae survival percentages were observed in maize $(46 \%)$, in comparison to okra $(13 \%)$, beans $(6 \%)$ and brinjal $(6 \%)$. However, that was not different from cabbage $(23 \%)$ and radish $(16 \%)$. In general, selected crops were female biased in survival. However, radish was male biased where, survival of male larvae (36\%) was compared to female (16\%). Sex identification of larvae was based on the visual observations after moth emergence.

Among the tested crops, the shortest life cycle of $S$. frugiperda was observed in maize. A similar result was reported by Meagher et al. (2004) compared to cowpea and sunnhemp. Moreover, maize showed a positive effect on larval growth, (i.e. greater pupal weights and pupal lengths) and development (short time taken by larvae to pupate and pupate to emergence of adults) compared to tested five vegetables (cabbage, okra, beans, radish and brinjal). Together with those factors, greater survival rates indicate the $S$. frugiperda preference on maize. Therefore, present study revealed that tested five vegetables were less preferred by $S$. frugiperda compared to the maize. This could be attributed to the quality of food; Barros et al. (2010), reported development of insects depends on the quality of the food. Similar results reviled that, this insect preference and best performance for grasses have been previously demonstrated by other researchers. In Buntin, (1986), Lewter et al. (2006) and Nagoshi et al. (2004) have shown that $S$. frugiperda preferred grasses such as maize, sorghum, and bermuda grass, which are C4 plants than C3 plants. And Silva et al. (2017) has identified grass species evaluated in his study were the most suitable host for the growth of $S$. frugiperda. At the same time, other researchers found that biochemical substances produced by plants under pest attack according to Hoffmann Campo et al. (2001) and Piubelli et al. (2005) influence the growth, survival, and reproduction of insects (Fischer et al., 1990).

Lower survival percentage of larvae was observed in brinjal, okra and beans, which were not significantly different, compared to maize, cabbage and radish. Lesser survival of larvae in above mentioned crops was difficult to justify due to reported greater natural mortality in the early larval stages of Lepidopteran (Zalucki et al., 2002). Moreover, smaller body size of first instar marks more difficulty in identification of living larvae. Previous studies (Bergvinson et al., 1994, Coley and Barone 1996, Hariprasad and van Emdem 2010, Gotoh et al., 2011 and Hong et al., 2012) have shown that the fiber 
content of leaves can affect the consumption of some Lepidoptera species and those hosts are representing an effective direct defense against herbivorous larvae. In this experiment the reproductive performance of survived insects was not studied.

\section{Host-plant preference for oviposition}

Among the tested vegetable crops in Choice experiment, $S$. frugiperda selected only maize and okra for oviposition (Figure 01 and Figure 02). Choice experiment suggested that female moths strongly preferred maize as their host than tested vegetables. Host preference for oviposition is highly varied with host plant quality. In general, female moths prefer oviposition on leaf surfaces where larval performance/ survival are greater (Craig et al., 1992; Meagher et al., 2004). This is in agreement with the present study; greater oviposition in maize under both free choice and
No-Choice experiments. Therefore, S. frugiperda female displays higher degree of preference/ specialization for the oviposition on maize. Rojas et al. (2018) indicated that oviposition by adult females was mediated by plant type, but not by seedling size and further said that ovipositional preference of females would positively be in relation with the performance of their larvae, including how larval performance takes place in the host. It also suggests that either ovipositing fall armyworm females discriminate among varieties or larvae preferentially select particular types of leaves in Wilmar et al. (2016). According to the Rojas et al. (2018) and Signoretti et al. (2012), the host-searching behavior of fall armyworm females has not been thoroughly investigated. But Carroll et al. (2006) reported that it has been shown that larvae can discriminate between healthy and herbivore-damaged plants and between different varieties of a plant according

Table 01: $\quad$ Male and female pupae weight (g) of $S$. frugiperda that feed on maize, cabbage, okra beans, radish and brinjal leaves under laboratory conditions.

\begin{tabular}{ccc}
\hline \multirow{2}{*}{ Host Plant } & \multicolumn{2}{c}{ Male and Female Pupae Weight $(\mathrm{g})$} \\
\cline { 2 - 3 } & Male & Female \\
\hline Maize & $0.26 \pm 0.01 \mathrm{a}$ & $0.22 \pm 0.005 \mathrm{a}$ \\
Cabbage & $0.17 \pm 0.01 \mathrm{~b}$ & $0.18 \pm 0.005 \mathrm{cb}$ \\
Okra & $*$ & $0.14 \pm 0.01 \mathrm{~d}$ \\
Beans & $0.19 \pm 0.01 \mathrm{~b}$ & $0.13 \pm 0.01 \mathrm{~d}$ \\
Radish & $0.17 \pm 0.004 \mathrm{~b}$ & $0.15 \pm 0.01 \mathrm{~cd}$ \\
Brinjal & $0.18 \pm 0 \mathrm{~b}$ & $0.19 \pm 0.0 \mathrm{~b}$ \\
\hline
\end{tabular}

Weights connected with same letters are not significantly different. $(n=3) .{ }^{*}$ Male moths were not emerged from the treatment Okra

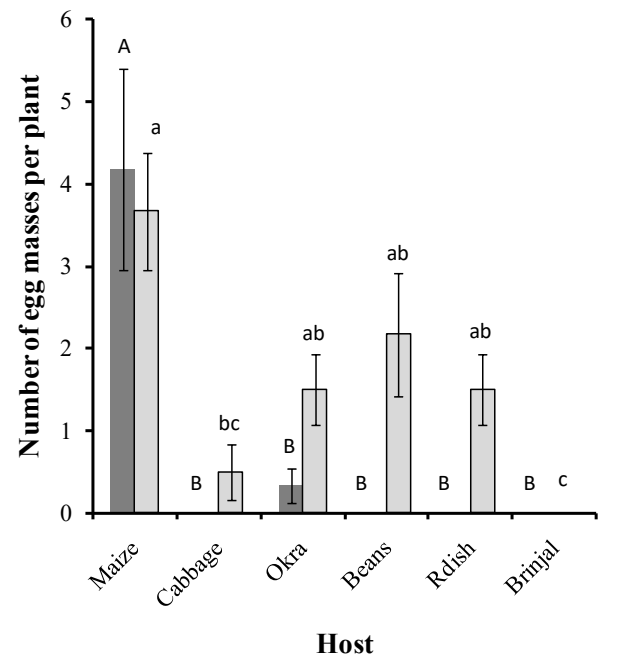

Figure 01: Number S. frugiperda egg masses per plant at Choice test (dark gray) and No-Choice (light gray) on maize, cabbage, okra beans, radish and brinjal leaves under laboratory condition. Numbers of egg masses per plant connected with same letters are not significantly different. $(n=3)$. 


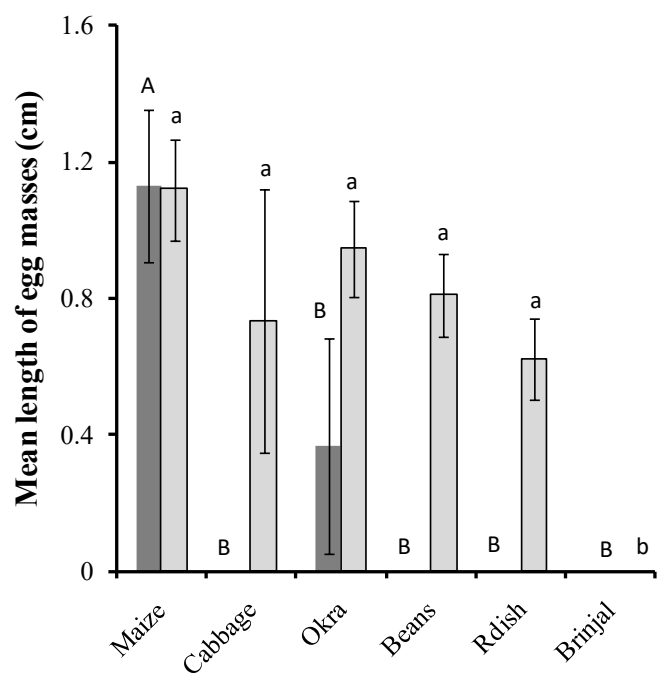

Host

Figure 02. Mean length of S. frugiperda egg masses at Choice test (dark gray) and No-Choice test (light gray) on maize, cabbage, okra beans, radish and brinjal under laboratory condition. Mean length of egg masses connected with same letters are not significantly different. $(\mathbf{n}=3)$.

to the results of Wilmar et al. (2015).

Egg masses were found in both sides of the leaf blade (upper and undersides) and this is in agreement with the findings of Silva et al. (2017). The number of eggs per egg mass and length of egg mass was not significantly different among the tested crops in No-Choice experiment. In No-Choice experiment oviposition was observed in all crops except brinjal. Therefore, in absence of preferred host (maize), okra, beans, radish and cabbage could act as an alternative host for $S$. frugiperda. Moreover, the result of present experiment suggested that, $S$. frugiperda may lay eggs in the alternative host in absence of their preferred host maize and it is in agreement with Meagher et al. (2004).

\section{Feeding preference of neonate larvae to test crops}

The number of larvae that feed on different host plants after introduction and their damage was significantly different $(\mathrm{p}<0.05)$ among the hosts (Table 02 and Table 03).1h, 3h, 24h and 48h after introduction, most number of the larvae was observed in maize and the lowest in brinjal. After one hour the number of larvae attracted to cabbage, okra and beans was not significantly different and Larvae were not examined on brinjal. After 3 hours the highest numbers of

Table 02: Distribution of $S$. frugiperda neonate larvae among host plants at $1 \mathrm{~h}, 3 \mathrm{~h}, 24 \mathrm{~h}$ and $48 \mathrm{~h}$ after introduction under laboratory conditions

\begin{tabular}{ccccc}
\hline \multirow{2}{*}{ Host } & \multicolumn{4}{c}{ Mean Larvae count } \\
\cline { 2 - 5 } & After 1 hour & After 3 hours & After 24 hours & After 48 hours \\
\hline Maize & $2.9 \mathrm{a}$ & $2.5 \mathrm{a}$ & $3.7 \mathrm{a}$ & $2.3 \mathrm{a}$ \\
Cabbage & $1.7 \mathrm{ab}$ & $2.0 \mathrm{ab}$ & $2.1 \mathrm{~b}$ & $1.8 \mathrm{a}$ \\
Okra & $1.6 \mathrm{ab}$ & $1.8 \mathrm{ab}$ & $1.5 \mathrm{bc}$ & $1.6 \mathrm{a}$ \\
Beans & $1.3 \mathrm{ab}$ & $1.5 \mathrm{abc}$ & $0.7 \mathrm{bc}$ & $0.3 \mathrm{~b}$ \\
Radish & $0.5 \mathrm{~b}$ & $0.7 \mathrm{bc}$ & $0.5 \mathrm{c}$ & $0.2 \mathrm{~b}$ \\
Brinjal & $0.0 \mathrm{~b}$ & $0.2 \mathrm{c}$ & $0.4 \mathrm{c}$ & $0.1 \mathrm{~b}$ \\
Total number of Dead larvae & & & &
\end{tabular}


Table 03: $\quad$ Percentage of damage caused by S.frugiperda at $24 \mathrm{hand} 48 \mathrm{~h}$ after introduction on maize, cabbage, okra, beans, radish and brinjal under laboratory condition

\begin{tabular}{ccc}
\hline \multirow{2}{*}{ Host } & \multicolumn{2}{c}{ Percentage of damage (\%) } \\
\cline { 2 - 3 } & 24 hours & 48 hours \\
\hline Maize & $<25 \%$ & $<25 \%$ \\
Cabbage & $<25 \%$ & $<25 \%$ \\
Okra & $<25 \%$ & $50-75 \%$ \\
Beans & $<25 \%$ & $25-50 \%$ \\
Radish & No significant damage & No significant damage \\
Brinjal & No significant damage & No significant damage \\
\hline
\end{tabular}

larvae were observed in the cabbage, okra and beans comparison to radish and brinjal among selected vegetables.

After 24 hours the highest number of larvae was observed in cabbage among vegetables. Most number of larvae was observed on maize, cabbage, okra was not significantly different after 48 hours and the lowest were examined in beans, radish and brinjal.

Results of the feeding preference test envisaged that there was no host dependent variability among neonate larvae for maize, cabbage, radish and brinjal. Although neonate larvae disperse on different hosts, the highest larval male and female survival $(80 \%)$ was reported on maize in life cycle test. Less preference was examined for radish and brinjal in the preference test. Rojas et al. (2018) reported that, neonate larvae would randomly colonize the available hosts immediately, but following colonization they may disperse in search of a host more suitable than the colonized host and ovipositional preference of females positively align with the performance of their larvae. It includes how larval performance may be mediated by expected (future) and ongoing (present) herbivory. Further they have identified neonate larvae would colonize hosts randomly and if they initially colonized poor hosts, older (3rd-instar) larvae orient towards and prefer hosts that would most favor their performance. When use of the 4 days old larvae for this experiment, larvae colonized on the maize and before end of the 24 hours, they feed on maize and damage was $100 \%$. After that they dispersed for others and fed on those hosts.

\section{CONCLUSION}

Greater oviposition, survival rate and shortest larva to adult period of Spodoptera frugiperda on maize indicate a higher host specialization/ preference. However, with the absence of preferred host, $S$. frugiperda use cabbage, okra, beans and radish as alternative host for the oviposition among selected crops. Therefore, the use of these vegetables in cropping systems for crop rotation and inter cropping would create a positive impact on off season survival of $\mathrm{S}$.

frugiperda by being alternative hosts. Result of this study concludes that growers should pay special attention when selecting vegetable crops in maize based upland cropping systems.

\section{REFERENCES}

Ayala, O., Navarro, F. and Virla, E.G. (2013).Evaluation of the attack rates and level of damages by the fall armyworm, Spodopterafrugiperda (Lepidoptera: Noctuidae), affecting corn-crops in the northeast of Argentina-Evaluación de lastasas de ataque y el nivel de dañospor el gusanocogollerodelmaiz, Spodopterafrugiperda (Lepidoptera: Noctuidae), en el noreste de Argentina. Revista de la Facultad de CienciasAgrarias. 45(2): pp 4-11 https://doi.org/10.19137/ semiarida.2018(01).1122

Barros, E., Torres, J.B., Ruberson, J.R. and Oliveira, M.D. (2010).Development of 
Spodopterafrugiperda on different hosts and damage to reproductive structures in cotton. EntomologiaExperimentalisetApplicata, 137: pp. 237-245. https://doi.org/10.1111/j.15707458.2010.01058.x

Bergvinson, D.J., Arnason, J.T., Hamilton, R., Mihm, J.A. and Jewell, D.C. (1994). Determining leaf toughness and its role in maize resistance to the european com borer (lepidoptera: Pyralidae). Journal of Economic Entomology, 87(6), pp.1743-1748. https://doi.org/10.1093/ jee/87.6.1743

Buntin, G.D. (1986). A review of plant response to fall armyworm, Spodoptera frugiperda (J.E. Smith), injury in selected field and forage crops. Florida Entomologist 69: 549-559. https://doi. org/10.2307/3495389

Carroll, M.J., Schmelz, E.A., Meagher, R.L. and Teal, P.E., 2006. Attraction of Spodoptera frugiperda larvae to volatiles from herbivore-damaged maize seedlings. Journal of chemical ecology, 32(9), pp.1911-1924. https://doi.org/10.1007/s10886-006-9117-9

Coley, P.D. and Barone, J.A. (1996). Herbivory and plant defenses in tropical forests. Annual review of ecology and systematics, 27(1), pp.305-335. https://doi.org/10.1146/annurev.ecolsys.27.1.305

Craig, T.P., Price, P.W. and Itami, J.K. (1992).Facultative sex ratio shifts by a herbivorous insect in to variation in host plant quality. Oecologia. 92: pp.153-163. https://doi.org/10.1007/ bf00317357

De La Rosa-Cancino, W., Rojas, J.C., Cruz-Lopez, L., Castillo, A. and Malo, E.A., 2016. Attraction, feeding preference, and performance of Spodoptera frugiperda larvae (Lepidoptera: Noctuidae) reared on two varieties of maize. Environmental entomology, 45(2), pp.384-389. https://doi. org/10.1093/ee/nvv229

FAO.(2018).Briefing Note on FAO Actions on Fall Armyworm in Africa 31 January 2018. In: Briefing Note on FAO Actions on Fall Armyworm in Africa 31 January 2018 FAO, Rome, Italy. 6 pp. https://doi.org/10.4060/cb1213t

FAO.(2019c). Briefing note on FAO actions on fall armyworm. Rome, Italy: FAO.6 pp. http://www. fao.org/3/a-bs183e.pdf. 16.06.2019

Fei Guo, J., Di Zhang, m., Peng Gao, Z., Jie Wang, D., Lai He, K. and Ying Wang, Z. (2020). Comparison of larval performance and oviposition preference of Spodoptera frugiperda among three host plants: Potential risks to potato and tobacco crops. Insct Science. https://doi. org/10.1111/1744-7917.12830

Fischer, D.C.; Kogan, M.; Paxton, J. (1990). Effect of glyceollin, a soybean phytoalexin, on feeding by three phytophagous beetles (Coleoptera: Coccinellidae and Chrysomelidae): dose versus response. Environmental Entomology 5: 1278-1282. https://doi.org/10.1093/ee/19.5.1278

Gotoh, T., Koyama, M., Hagino, Y. and Doke, K. (2011). Effect of leaf toughness and temperature on development in the lilac pyralid, Palpita nigropunctalis (Bremer)(Lepidoptera: Crambidae). Journal of Asia-Pacific Entomology, 14(2), pp.173-178. https://doi.org/10.1016/j. aspen.2010.12.011

Hardke, J.T., Lorenz, G.M. and Leonard, B.R. (2015). Fall armyworm (Lepidoptera: Noctuidae) ecology in southeastern cotton. Journal of Integrated Pest Management. 6 (1): p.10. https://doi. org/10.1093/jipm/pmv009 
Hariprasad, K.V. and van Emden, H.F. (2010). Mechanisms of partial plant resistance to diamondback moth (Plutella xylostella) in brassicas. International journal of pest management, 56(1), pp.1522. https://doi.org/10.1080/09670870902980834

Hendrix, P.F., Coleman, D.C. and Crossley Jr, D.A., 1992. Using knowledge of soil nutrient cycling processes to design sustainable agriculture. Journal of Sustainable Agriculture, 2(3), pp.63-82. https://doi.org/10.1300/j064v02n03_06

Hoffmann-Campo, C.B., Harbone, J.B. and McAffery, A.R. (2001). Preingestive and post-ingestive effects of soya bean extracts and rutin on Trichoplusia ni growth. Entomologia Experimentalis et Applicata 98: 181-194. https://doi.org/10.1046/j.1570-7458.2001.00773.x

Hong, S.C., Williamson, R.C. and Held, D.W. (2012). Leafbiomechanical properties as mechanisms of resistance to black cutworm (A grotis ipsilon) among P oa species. Entomologia Experimentalis et Applicata, 145(3), pp.201-208. https://doi.org/10.1111/eea.12005

Lewter, J.A., Szalanski, A.L., Nagoshi, R.N., Meagher, R.L., Owens, C.B. and Luttrellm, R.G. (2006). Genetic variation within and between strains of the fall armyworm, Spodoptera frugiperda (Lepidoptera: Noctuidae). Florida Entomologist 89: 63-68. https://doi.org/10.1653/00154040(2006)89[63:gvwabs]2.0.co;2

Meagher, R.L., Nagoshi, R.N., Stuhl, C. and Mitchell, E.R.(2004).Larval developmentoffall armyworm (Lepidoptera: Noctuidae) on different cover crop plants. Florida Entomologist. 87(4): pp.454461. https://doi.org/10.1653/0015-4040(2004)087[0454:1dofal]2.0.co;2

Nagoshi, R.N. and Meagher, R.L. (2004). Behavior and distribution of the two fall armyworm host strains in Florida. Florida Entomologist, 87(4), pp.440-450. https://doi.org/10.1653/00154040(2004)087[0440:badott]2.0.co;2

Perera, N., Magamage, M., Kumara, A.,Galahitigama, H., Dissanayake, K., Wekumbura, C., Iddamalgoda, P., Siriwardhana, C. and Yapa, P. (2019). Fall armyworm (faw) epidemic in Sri Lanka: Ratnapura district perspective. International Journal of Entomological Research. 07(01): pp. 9-18. https://doi.org/10.33687/entomol.007.01.2887

Piubelli, G.C., Hoffmann-Campo, C.B., Moscardi, F., Miyakubo, S.H. and Oliveira, M.C.N. (2005). Are chemical compounds important for soybean resistance to Anticarsia gemmatalis? Journal of Chemical Ecology 31: 1509-1525. https://doi.org/10.1007/s10886-005-5794-z

Rojas, J.C., Kolomiets, M.V. and Bernal, J.S. (2018).Nonsensical choices? Fall armyworm moths choose seemingly best or worst hosts for their larvae, but neonate larvae make their own choices. PloS one, University of Tennessee, united states.13(5): p.e0197628. https://doi. org/10.1371/journal.pone.0197628

Signoretti, A.G.C., Peñaflor, M.F.G.V. and Bento, J.M.S. (2012). Fall armyworm, Spodoptera frugiperda (JE Smith)(Lepidoptera: Noctuidae), female moths respond to herbivore-induced corn volatiles. Neotropical entomology, 41(1), pp.22-26. https://doi.org/10.1007/s13744-0110003-y

Silva, D.M.D., Bueno, A.D.F., Andrade, K., Stecca, C.D.S., Neves, P.M.O.J. and Oliveira, M.C.N.D. (2017). Biology and nutrition of Spodopterafrugiperda (Lepidoptera: Noctuidae) fed on different food sources. Scientia Agricola. 74(1): pp.18-31. https://doi.org/10.1590/1678-992x-2015-0160

Zalucki, M. P., A. R. Clarke, and S. B. Malcom. (2002). Ecology and behavior of first instar larval Lepidoptera. Annu. Rev. Entomol. 47: pp. 361-393. https://doi.org/10.1146/annurev. ento.47.091201.145220 